\title{
Binarity in Prosodic Morphology and Elsewhere
}

\author{
Gloria Mellesmoen and Suzanne Urbanczyk \\ University of British Columbia and University of Victoria
}

\section{Introduction}

McCarthy and Prince (1986/1999: 238) ushered in the field of prosodic morphology with the following: "Consider the role of counting in grammar. How long may a count run? [...] the answer is probably "up to two' [...]". This is consistent with other proposals about the architecture of the grammar: there is only binary branching in morphology and syntax (Aronoff 1976; Kayne 1984). Binarity is a component of prosodic morphology as well, utilized to account for certain phenomena, such as metrical feet (Hayes 1995), and guiding some models of syllable structure (Kaye, Lowenstamm, \& Vergnaud 1990). We further refine the role of binarity in phonology by proposing that all phonological representations are binary branching, as stated in (1).

(1) Binarity Hypothesis: All representations are maximally binary branching.

Our evidence comes from examining patterns in which the fission and fusion of segments satisfy constraints on well-formed phonological and morphological structures: multiple reduplication, haplology, coalescence, and breaking.

The domain of investigation for this paper is the mapping of segments between input and output. Patterns of fission and fusion are primarily 1:2 (fission) or 2:1 (fusion). To account for instances that appear to have 1:3 or 3:1 mappings between input and output segments, we propose that this must arise from two separate 1:2 mappings (perhaps at a stem and word level). The following section outlines a range of potentially problematic 1:3 mappings related to fission of segments and INTEGRITY violations. We then point out a critical formal problem (computational indeterminacy) with how INTEGRITY violations are calculated in the analysis of multiple reduplication in $\S 3$. Section $\S 4$ examines the Binarity Hypothesis in the context of fusion phenomena and UNIFORMITY violations, and we present our conclusions for binarity in the architecture of the grammar in $\S 5$.

\section{Fission \& INTEGRITY violations}

The Prosodic Morphology Hypothesis states that "templates are defined in terms of the authentic units of prosody..." (McCarthy \& Prince 1990: 209). The prosodic units are then filled by mapping segments from the base to the prosodic units (McCarthy \& Prince 1986, 1990). This has been successfully modeled in Optimality Theory (OT; Prince \& Smolensky 1993/2004) by having morphemes, which are prosodic units in the input, filled in the output by the fission of segments, which violates INTEGRITY (Bermúdez-Otero 2012; Bye \& Svenonius 2012; Saba Kirchner 2010, 2013; Zimmerman 2017, to appear).

INTEGRITY (McCarthy \& Prince 1999: 296)

No element of $\mathrm{S}_{1}$ has multiple correspondents in $\mathrm{S}_{2}$.

Note that the phrase "multiple correspondents" does not restrict the number of correspondents to two, so there could potentially be any number of correspondents. In words with a single instance of reduplication, there is only one fission and one input segment maps to two output segments. This 1:2 input-output mapping respects binarity. However, when there is more than one reduplicative morpheme, there is the potential to

\footnotetext{
${ }^{*}$ We would like to thank the audience of AMP 2020 for their great feedback and questions. We dedicate this paper to Sti'tum'at - Ruby Peter - who dedicated her life to documenting, teaching and revitalizing Hul'q'umi'num'. She always shared her knowledge of Hul'q'umi'num' graciously and with great wisdom and humour.
}

(C) 2021 Gloria Mellesmoen, Suzanne Urbanczyk

Proceedings of $A M P 2020$ 
have multiple violations of INTEGRITY, as implemented in Zimmermann's (to appear) analysis of multiple reduplication (MR), which uses 1:3 mappings. Our analysis of the same pattern, which is consistent with The Binarity Hypothesis proposed in (1) has a number of advantages, which we present in the following sections (§2.1 and $\S 2,2)$.

2.1 Deriving multiple reduplication Lushootseed (Central Salish) has MR patterns, where a single word may have more than one reduplicative morpheme. Multiple reduplication in Lushootseed has been proposed to follow from various grammatical principles, such as morphological subjacency (Broselow 1983), parallelism (Urbanczyk 2006), and prosodic truncation (Zimmermann to appear).

The reduplicative patterns in Lushootseed are presented below with diminutive $\mathrm{C}_{1}(3 \mathrm{~b})$ and distributive $\mathrm{C}_{1} \mathrm{C}_{2}(3 \mathrm{c})$ reduplication. ${ }^{2}$ Note that words can be created with multiple reduplication to express both meanings (3d). We note that both orders are attested (3d-e), though the last pattern is rare. The fixed segment [i] in (3b) and (3e) emerges as a way to avoid a stressed schwa with diminutive $C_{1}$ reduplication (Alderete et al. 1999; Urbanczyk 2006)

\begin{tabular}{|c|c|c|}
\hline $\begin{array}{l}\text { Lushootseed rec } \\
\text { a. bəda? }\end{array}$ & elow 1983; & \\
\hline b. bí-bədà? & small child & $\mathbf{C V}$ DIM \\
\hline c. bəd-bədá? & children & CVC \\
\hline d. bí-bi-bodá? & small children & $\mathbf{C} \mathbf{V}_{\text {DIST }} \mathbf{C} \mathbf{V}_{\text {DIM }}$ \\
\hline e. bí-bəd-bədà? & litter (of animals); dolls & $\mathbf{C V} \mathbf{V}_{\text {DIM }} \mathbf{C V} \mathbf{C}_{\text {DIST }}$ \\
\hline
\end{tabular}

Two unexpected phonological aspects of the pattern that are central to these theoretical proposals are exemplified by the distributive-diminutive word in (3d): the distributive is CV-shaped, rather than CVCshaped, and the diminutive has the default [i] without the triggering context of stress.

We propose that double reduplication occurs in multiple steps: diminutive reduplication is a stem-level process, with one violation of INTEGRITY, and distributive reduplication is a word-level process (that applies to the diminutive stem). Furthermore, this stratal analysis accounts for the patterns better than one which involves a 1:3 mapping in a single stage. The fixed default vowel [í] arises at the stem-level, to avoid stressing a schwa, as indicated in (4a). The distributive then takes the diminutive stem as the input with the vowel [i] available to the distributive for copying. This stratal analysis accounts for why both reduplicants have [i]. The failure to copy the second consonant is due to a prohibition on geminates in Lushootseed (Urbanczyk 2006). Note that the two-stage analysis in (4a) only involves 1:2 mappings between segments and therefore is consistent with the Binarity Hypothesis. This differs from the approach that Zimmermann (to appear) presents, in which there is a single 1:3 mapping, as indicated in (4b).

a. Stratal with Binarity

Stem $\quad \sigma_{\mu-}-\bigwedge_{\text {bí-bəda? }}^{\text {borda? }}$ b. Not Binary, not emitted by Gen

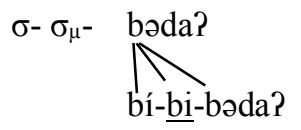

We note two types of problems with a monostratal ternary branching approach to Lushootseed double reduplications (as in 4b). The first is empirical: it cannot account for the vowel quality of the reduplicants. Zimmermann's (to appear: 18) explanation for why the vowel is not schwa is that a markedness constraint bans schwa in open syllables in reduplication: she "analyze[s] this as an Emergence of the Unmarked Effect that avoids open ə-syllables". ${ }^{3}$ It is crucial that stress not be a condition in Zimmermann's approach because

\footnotetext{
${ }^{2}$ The label "distributive" is borrowed from the literature, but we note that "plural" would be a more accurate label for this type of reduplication. The $\mathrm{C}_{1} \mathrm{C}_{2}$ reduplication called "distributive" in Lushootseed is cognate to the $\mathrm{C}_{1} \mathrm{C}_{2}$ "plural" reduplication called "plural" in Halkomelem.

${ }^{3}$ We also note that it is not clear how Emergence of the Unmarked effects are derived without Base-Reduplicant Correspondence Relation in models that achieve copying via INTEGRITY violations.
} 
the second syllable has [i] but is unstressed. However, there is a great deal of evidence that stress is the triggering context. Examples of schwa in reduplicated open syllables occur with all reduplicative morphemes in Lushootseed; the context is always when it is unstressed. A feature of diminutive words is that they have initial stress, but in the cases where stress is non-initial, schwa is found, as in (5). ${ }^{4}$

$$
\begin{aligned}
& \text { Lushootseed unstressed schwas in diminutive reduplication (Bates, Hess, \& Hilbert 1994) }
\end{aligned}
$$

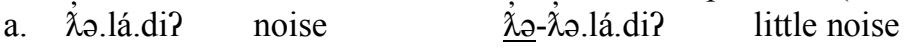

$$
\begin{aligned}
& \text { b. syə.húb traditional story s-yə-yə.húb } \\
& \text { c. gwád talk g ge-gwá.dəd } \\
& \text { d. } \mathrm{n} / \mathrm{a} \\
& \text { qa-qíl }
\end{aligned}
$$

In addition to the complications noted regarding deriving the segmental quality of the reduplicants, Zimmermann's (to appear) analysis has a number of issues deriving the CV- shape of the distributive reduplicant under her 'Subtracting Multiple Reduplication' classification. First, she analyzes distributivediminutive words as in (3d), with the input order of diminutive-distributive, represented by prosodic units in the input as follows: $/ \mu_{1}+\mu_{2} \mu_{3}+$ root/. This is a different order than the surface form. Second, in order to derive the CV-shape of the distributive as an example of Subtracting MR, she proposes fusion of the mora from the diminutive morpheme with the second mora from the distributive morpheme, with the optimal form having the output structure for distributive-diminutive words as $\left[\mu_{1,2}+\mu_{3}\right]$. This fusion of moras is compelled in order to avoid INTEGRITY violations. If this forced mora fusion occurs with the distributive moras to avoid copying an extra segment, how then, can any distributive words be derived with the same ranking? Finally, Occam's Razor is decisive here: this complex affix reordering + mora fusion analysis is unnecessary, as the $\mathrm{CV}$-shape follows naturally from a restriction on geminates in Lushootseed.

This latter critique of simplicity also extends to the analysis Zimmermann (to appear) presents of the avoidance of MR in Nuu-chah-nulth, which has over 80 affixes which can trigger reduplication. Regardless of the number of reduplication-triggering morphemes in the word, the maximum number of reduplicants in any word is two. Stonham (2007) presents evidence from a wide range of phonological processes and phonotactic conditions including some morphophonological processes, which support only having one reduplication process occur at the stem-level and one at the word-level. All doubly reduplicated words in Nuu-chah-nulth are then derived by the same general approach as in (4a): one reduplication at the stem-level and then one at the word-level. Rather than introducing constraints to ban reduplication, this pattern is predicted with the Binarity Hypothesis. Nothing more needs to be said. The second critique of the 1:3 mapping approach is formal in nature and relates to what we refer to as computational indeterminacy; we defer discussion of the formal issues to $\S 3$, after discussing other predictions.

2.2 Avoiding ternary branching in one level The Binarity Hypothesis also makes predictions regarding reduplication and the expression of prosodic morphemes when they occur at the same level. With MR, both morphemes cannot be expressible with reduplication because that would involve more than one INTEGRITY violation, which is predicted to be impossible. In that case, one option is to avoid reduplication for one of the morphemes. The other option is to have reduplication fill one part of the prosodic structure and gemination fill the other: gemination involves spreading to a mora and doesn't involve multiple segment mapping. We note that this latter strategy to avoid a 1:3 mapping can also occur with just one morpheme.

We start by discussing a pattern of reduplication avoidance found in Halkomelem (Central Salish) verbs. The three relevant reduplicative morphemes are: the imperfective, diminutive, and plural. In Hul'q'umi'num' (the dialect of Halkomelem spoken on Vancouver Island), plural reduplication occurs at the same stratum as 'diminutive'. However, the plural has a non-reduplicative allomorph -1-, and it is used to express the plural when it co-occurs with the diminutive. We analyze the imperfective as a stem-level affix, and the diminutive and plural as both word-level affixes. ${ }^{5}$ When the diminutive is applied to verbs, they are usually also marked with imperfective morphology. The imperfective morpheme has many non-concatenative allomorphs, which are phonologically conditioned (see Mellesmoen \& Urbanczyk 2020 for full analysis of the imperfective as

${ }^{4}$ Syllables in (5) are indicated with a period, when syllable boundaries do not correspond with reduplicative boundaries.

${ }^{5}$ We sketch out the data and general approach here, and refer those interested in the full OT analysis to see Mellesmoen \& Urbanczyk (to appear) for more details. 
mora affixation). When the imperfective is formed by a non-reduplicative exponent as in (6a) the diminutive is $\mathrm{C}_{11} \mathrm{i}$. When the imperfective is formed by reduplication, the diminutive reduplication is $\mathrm{C}_{1}$-, as in (6b). Note that multiple reduplication in $(6 \mathrm{~b})$ is possible because diminutive reduplication applies at the word-level (to the output of the stem-level).

$$
\begin{aligned}
& \text { Hul'q'umi'num' dim-imperfective (Hukari \& Peter 1995; Mellesmoen \& Urbanczyk to appear) } \\
& \text { Imperfective } \\
& \text { a. C } \mathrm{C}_{1} \mathrm{i} \text { ' k'élt 'pouring it' } \\
& \text { خ̀épx̣t 'sprinkling it' } \\
& \text { b. C1ə- láłək }{ }^{\mathrm{w}} \text { 'flying' } \\
& \text { téłəqə⿳亠口冋’ 'whispering' }
\end{aligned}
$$

\begin{tabular}{|c|c|}
\hline \multicolumn{2}{|c|}{ Diminutive-Imperfective } \\
\hline kwi?k"éłt & 'pouring it (dim.)' \\
\hline 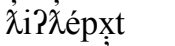 & 'sprinkling it (dim.)' \\
\hline łəłá Płək ${ }^{\mathrm{w}}$ & 'flying (dim.)', \\
\hline łəłéPłəqəm & 'whispering (dim.)' \\
\hline
\end{tabular}

\begin{tabular}{|c|c|c|c|c|}
\hline \multicolumn{5}{|c|}{ Hul'q'umi'num' plural } \\
\hline $\mathrm{C}_{1} \partial \mathrm{C}_{2-}$ & tíləm & 'to sing' & təol-tíləm & 'they sing' \\
\hline & lémət & 'to look at s.t.' & ləm-lémət & 'to look at them' \\
\hline b. $\quad-1-$ & ném & 'go' & néləạm & 'they go' \\
\hline & $\mathrm{k}^{\mathrm{w} e ́ s}$ & 'hot (get hot)' & $\mathrm{k}^{\mathrm{w}} \underline{\underline{e} l e \mathrm{~s}}$ & 'hot, warm weather' \\
\hline & técəl & ‘arrive, reach’ & téläcal & ‘arrive pl’ \\
\hline
\end{tabular}

As can be seen in (7), the plural morpheme can take one of two forms with verbs: a $\mathrm{C}_{1} \mathrm{C}_{2}$ - reduplicant and an /-1-/ infix

When plural is added to words that also have the diminutive and imperfective morphemes, the $-l$ - infix is used, rather than reduplication, as can be seen in (8).

$$
\begin{aligned}
& \text { Hul'q'umi'num' dim-imperfective-plural } \\
& \text { Diminutive-Imperfective } \\
& \text { a. liłłəłónəm 'weaving (dim)' } \\
& \text { b. pirpaqwt 'breaking it (dim)' }
\end{aligned}
$$

\author{
Diminutive-Imperfective-Plural \\ łəliłłəłə́nəm 'weaving (dim-pl)' \\ poli?paq ${ }^{w t} \quad$ 'breaking them (dim)'
}

We note that the failure of reduplication to arise in words where multiple morphemes with reduplicative exponents are present is predicted, based on the Binarity Hypothesis, because it would require ternary mapping with if two or more morphemes were in the same stratum. A candidate like *pi?-paq ${ }^{w}-p a q^{w} t$, with two copies of the /p/ would never be generated, according to the Binarity Hypothesis.

The second set of predictions regarding ternary mappings in prosodic morphology is that there should be languages in which the prosodic template can be filled by reduplication plus gemination. We have found this pattern in Woleaian (Kennedy 2003), as well as Mayo and Hiaqui (Haugen 2003). Examples from Hiaqui are presented in (9). This is one of the allomorphs of the habitual morpheme, which occurs when the first syllable is heavy; this 1:3 mapping cannot be analyzed as arising in two separate strata, because it is a single morpheme.

(9) Hiaqui marked heavy syllable reduplication (Haugen 2003)
a. bwii.ka 'sing'
bwib.bwika
b. tee.ka
'lay it across'
tet.te.ka
c. va.hu.me 'swim'
vav.va.hu.me
d. ye.na 'smoke (tobacco)
yey.ye.na

We propose the pattern in (10), whereby Hiaqui heavy syllable reduplication involves both reduplication (and an INTEGRITY violation), as in (10a), and gemination, as in (10b). Note that the mapping for reduplication is still a 1:2 input-output segment mapping, consistent with the Binary Hypothesis, and that gemination occurs via spreading to fill the mora in the coda, so it does not involve any additional INTEGRITY violations. 
Hiaqui heavy syllable reduplication and gemination
a. IO-Mapping
b. Prosodic Mapping
INTEGRITY
Gemination
Input:

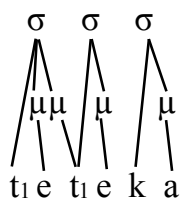
$\rightarrow \quad$ tet.te.ka]

Having established that there are various ways that apparent 1:3 mappings can be analyzed so that they conform to the Binarity Hypothesis, we now turn to a formal issue with ternary mapping that we refer to as computational indeterminacy.

\section{Computational Indeterminacy}

The formal definition of INTEGRITY, originally given in (2) and restated in (11) bans multiple correspondents.

INTEGRITY (McCarthy \& Prince 1999: 296)

No element of $\mathrm{S}_{1}$ has multiple correspondents in $\mathrm{S}_{2}$.

There is no further restriction or clarification on what counts as a violation aside from the presence of multiple output correspondents. In the case of multiple reduplication, there are several ways that INTEGRITY can be violated. If two segments are doubled, as in (12a), one INTEGRITY violation is incurred for each segment that is doubled, giving two violations. However, if the vowel is not copied as in (12b), but the consonant has three correspondents, that also results in two INTEGRITY violations.

(12) Computational Indeterminacy in INTEGRITY violations.

\begin{tabular}{|c|c|}
\hline & INTEGRITY \\
\hline a. bəda? & $* *$ \\
\hline b. bəda? & $* *$ \\
\hline
\end{tabular}

Both candidate mappings in (12) fare the same on INTEGRITY violations. Candidate (12a) incurs one violation for doubling the consonant and one violation for doubling the vowel. Candidate (12b) incurs two violations as well, but in this case, all three output segments map to a single input segment (the consonant). There are two 1:2 mappings in (12a), but one 1:3 mapping in (12b), and (12b) is consistent with Zimmermann's (to appear) approach to MR using INTEGRITY. All things being equal, it is not possible for EVAL to choose which candidate is optimal. However, under the Binarity Hypothesis, a 1:3 candidate like the one in (12b) would never be generated; this type of computational indeterminacy (under INTEGRITY) does not arise.

A second type of prediction related to this computational indeterminacy of INTEGRITY violations arises when the prosodic affix is a foot. If ternary mappings between input and output are permitted, then candidate (13a) would have four violations: two for the first consonant having two correspondents, and two for the first vowel having two correspondents. Candidate (13b) would also have four INTEGRITY violations, one for each of the four segments that are doubled. In this situation, the reduplicant shapes are the same, and the computational indeterminacy is even more pronounced. What would rule out candidates like (13a) which fill a bimoraic foot template. Both patterns are expected to occur. However, we are not aware of any language 
that fills a foot template by mapping the first syllable of a polysyllabic base twice, when the base has sufficient segments to map to a foot. If it does happen, it is exceedingly rare; we only know of cases where the base is smaller than the foot template, such as in Kinande (Mutaka \& Hyman 1990). The typological gap of patterns like (13a) is predicted by the Binarity Hypothesis.

(13) Hypothetical foot reduplication

\begin{tabular}{|c|c|}
\hline Foot $-\mathrm{p}_{1} \mathrm{a}_{2} \mathrm{~m}_{3} \mathrm{u}_{4}$ tul & INTEGRITY \\
\hline a. $\quad \mathrm{p}_{1} \mathrm{a}_{2} \mathrm{p}_{1} \mathrm{a}_{2}-\mathrm{p}_{1} \mathrm{a}_{2} \mathrm{~m}_{3} \mathrm{u}_{4} \mathrm{tul}$ & $* * * *$ \\
\hline b. $\quad \mathrm{p}_{1} \mathrm{a}_{2} \mathrm{~m}_{3} \mathrm{u}_{4}-\mathrm{p}_{1} \mathrm{a}_{2} \mathrm{~m}_{3} \mathrm{u}_{4}$ tul & $* * * *$ \\
\hline
\end{tabular}

We now turn our attention to cases in which the mirror-image type of mapping occurs, a 2:1 mapping from input to output that is found in patterns of fusion, which incur UNIFORMITY violations.

\section{Fusion \& UNIFORMITY violations}

The Binarity Hypothesis states that phonological structures are maximally binary branching, which we have explored in the context of INTEGRITY violations and fission patterns found in reduplication. The Binarity Hypothesis rules out 1:3 mappings in fission, but it makes an equally strong prediction in the opposite direction: 3:1 mappings in fusion (which violate UNIFORMITY, rather than INTEGRITY) should be equally impossible. The formal definition of UNIFORMITY is provided below.

UNIFORMITY (McCarthy and Prince 1999: 296)

No element of $\mathrm{S}_{2}$ has multiple correspondents in $\mathrm{S}_{1}$.

As noted in the definition, there is reference to multiple correspondents, but in this case the mapping is from the multiple input elements to a single output element. Processes that violate UNIFORMITY include coalescence or fusion, as well as haplology. The former is fusion of multiple segments, while the latter is fusion of multiple morphemes.

Under the Binarity Hypothesis, a 3:1 mapping cannot be generated, even in cases where coalescence or haplology are observed. This prediction has typological support: Nevins' (2012) cross-linguistic investigation of haplology patterns reveals no cases in which three segmentally identical input morphemes are realized as one output morpheme. In terms of segmental coalescence, we note that all cases cited in Wheeler (2005) involve coalescence of only two segments, and we have found only one putative case of a 3:1 mapping: Norwegian retroflexion and cluster reduction.

In Norwegian, suffixation to an obstruent-final root cluster creates a tri-consonantal sequence, as in (15) which may either surface unchanged, or be realized as a single segment in the output and interacts with retroflexion patterns (15a). There are also cases where the mapping is to two segments (15b).

$$
\begin{aligned}
& \text { Norwegian coalescence and retroflexion (Kristoffersen 2000:109) }
\end{aligned}
$$

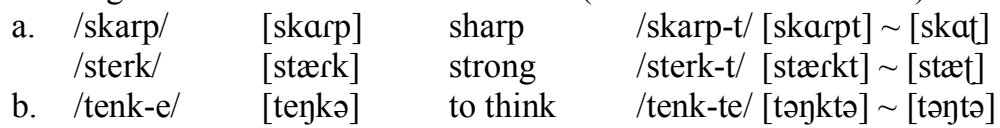

While there are very few patterns that could be analysed as 3:1 mappings in the literature on coalescence and haplology, examples like the ones in (15a) from Norwegian challenge the Binarity Hypothesis if $r_{l} p_{2} t_{3}$ in the input corresponds to $t 1,2,3$ in the output, as this would indicate a phonological structure that is not binary branching. However, this is only an issue if the entire coalescence process occurs at a single (parallel) point in the derivation. The Norwegian data does not pose a problem for the Binarity Hypothesis if treated in twostage analysis (echoing that proposed for fission in MR). ${ }^{6}$

We treat the coalescence in (15a) as involving two processes: deletion of the medial consonant and coalescence, which causes the retroflexion. The input $r_{1} p_{2} t_{3}$ corresponds to $t 1,3$, with the medial $/ \mathrm{p} / \mathrm{being}$

\footnotetext{
${ }^{6}$ See Kristoffersen's (2000) description of Norwegian retroflexion and cluster simplification, which is presented within Lexical Phonology, for more evidence that a multiple-stage approach is appropriate for this data in the context of the language.
} 
deleted, incurring a violation of MAX, rather than UNIFORMITY. Note that the apparent 3:1 fusion in (15a) is variable, and retroflexion only occurs where the medial $/ \mathrm{p} / \mathrm{or} / \mathrm{k} /$ has been deleted, supporting the distinction of the apparent 3-to-1 coalescence into two processes: deletion and retroflexion/coalescence. The analysis is further supported by the non-retroflexion pattern in $(15 \mathrm{~b})$, where the medial stop $/ \mathrm{k} /$ is subject to variable deletion, but an earlier process of nasal assimilation, triggered by $/ \mathrm{k} /$, is retained. The Norwegian data in (15) do not involve a ternary (3:1 mapping) phonological structure and therefore the Binarity Hypothesis holds.

The next step, though beyond the scope of the present paper, is to investigate whether the Binarity Hypothesis extends beyond the segment level, to consider how this accounts for phonological structures involving other phonological items, such as sub-segmental features or suprasegmental tones. If the Binarity Hypothesis holds elsewhere, we predict that instances of putative 3:1 or 1:3 mappings may actually involve binary branching if recast as two-stage fission or fusion. In addition to this, there is a formal symmetry between how INTEGRITY and UNIFORMITY are defined. Interestingly, this doesn't seem to match the empirical findings about expected patterns of fission and fusion, which also warrants further examination. The computational indeterminacy noted with the calculation of INTEGRITY violations may have a parallel in the evaluation of UNIFORMITY.

\section{Conclusion}

The discussion above shows that 1:3 and 3:1 segmental mappings are typologically rare or absent, and that even putative cases of ternary mappings can be successfully modeled as a sequence of two 1:2 or 2:1 mappings. We have also discussed a number of issues that arise with the computational indeterminacy of how INTEGRITY violations are calculated. The conclusion from this investigation is that segmental mappings are in essence binary and hence follow the Binarity Hypothesis presented in this paper.

The question then arises as to where the restriction to binarity is located. Is binarity in the definitions of the faithfulness constraints themselves or in the architecture of the grammar, i.e. a property of GEN? Given the overwhelming evidence for binarity in morphology and syntax, we argue that the explanation lies in the architecture of the grammar, and is the motivation behind proposing the Binarity Hypothesis. This location of the constraint on UG is also consistent with a long-stated goal of phonological theory: "An explanation is something that satisfies one until one has looked deeper; then one asks for an explanation of the explanation" (Hockett 1955: 4).

\section{References}

Alderete, John, Jill Beckman, Laura Benua, Amalia Gnanadesikan, \& John McCarthy. 1999. Reduplication with fixed segmentism. Linguistic Inquiry, 30: 327-64.

Aronoff, Mark. 1976. Word formation in generative grammar. MIT Press.

Bates, Dawn, Thom Hess, \& Vi Hilbert. 1994. Lushootseed dictionary. University of Washington Press.

Bermúdez-Otero, Ricardo. 2012. The architecture of the grammar and division of labor in exponence. In Jochen Trommer (ed). The morphology and phonology of exponence. Oxford University Press, 8-83.

Broselow, Ellen. 1983. Salish double reduplications: Subjacency in morphology. Natural Language and Linguistic Theory, 1: 317-346.

Bye, Patrik, \& Peter Svenonius. 2012. Non-concatenative morphology as epiphenomenon. In Jochen Trommer (ed). The morphology and phonology of exponence. Oxford University Press, 427-495.

Haugen, Jason. 2003. Allomorphy in Yaqui reduplication. Studies in Uto-Aztecan, 75-103.

Hayes, Bruce. 1995. Metrical stress theory: Principles and case studies. University of Chicago Press.

Hockett, Charles. 1955. A manual of phonology. University of Chicago Press.

Hukari, Tom, \& Ruby Peter. 1995. Cowichan dictionary. Cowichan Tribes.

Kaye, Jonathan, Jean Lowenstamm, \& Jean-Roger Vergnaud. 1990. Constituent structure and government in phonology. Phonology, 7: 193-231.

Kayne, Richard. 1984. Connectedness and binary branching. Foris, Dordrecht.

Kennedy, Robert. 2003. Confluence in phonology: evidence from Micronesian reduplication (Doctoral dissertation).

Kristoffersen, Gjert. 2000. The phonology of Norwegian. Oxford University Press on Demand.

Mellesmoen, Gloria \& Suzanne Urbanczyk. 2020. Mora affixation and Halkomelem imperfective allomorphy. In D. K. E. Reisinger, Hannah Green, Marianne Huismans, Gloria Mellesmoen \& Bailey Trotter (eds.) Papers for the International Conference on Salish and Neighbouring Languages 55. UBC Working Papers in Linguistics.

Mellesmoen, Gloria, \& Suzanne Urbanczyk. to appear. Avoiding multiple reduplication without INTEGRITY. In Rachel Soo \& Daniel Reisinger (eds). Proceedings of the West Coast Conference on Formal Linguistics 37. Cascadilla Press. 
McCarthy, John, \& Alan Prince. 1986. Prosodic morphology. Ms., UMass \& Brandeis University.

McCarthy, John, \& Alan Prince 1990. Foot and word in prosodic morphology: The Arabic broken plural. Natural Language \& Linguistic Theory, 8: 209-283.

McCarthy, John, \& Alan Prince. 1999. Faithfulness and Identity in Prosodic Morphology. In René Kager, Harry van der Hulst, \& Wim Zonneveld (eds.) The prosody-morphology interface. Cambridge University Press, 218-309.

Mutaka, Ngessimo, \& Larry M. Hyman. 1990. Syllables and morpheme integrity in Kinande reduplication. Phonology 7: $73-119$

Nevins, Andrew. 2012. Haplological dissimilation at distinct stages of exponence. In Jochen Trommer (ed). The morphology and phonology of exponence. Oxford University Press, 84-116.

Prince, Alan, \& Paul Smolensky. 1993/2004. Optimality theory: Constraint interaction in generative grammar. Malden, MA \& Oxford: Blackwell. [Revision of 1993 technical report, Rutgers University Center for Cognitive Science. Available on Rutgers Optimality Archive, ROA-537]

Saba Kirchner, Jesse. 2010. Minimal reduplication (Doctoral dissertation.).

Saba Kirchner, Jesse. 2013. Minimal reduplication and reduplicative exponence. Morphology, 23: 227-243.

Urbanczyk, Suzanne. 2006. Reduplicative form and the root-affix asymmetry. Natural Language and Linguistic Theory, 24: $179-240$.

Wheeler, Max. 2005. Cluster reduction: deletion or coalescence. Catalan Journal of Linguistics, 4: 57-82.

Zimmermann, Eva. 2017. Morphological length and defective morphemes. Oxford University Press.

Zimmermann, Eva. to appear. Two is too much. . . in the phonology! A phonological account of avoidance and subtraction in multiple reduplication. The Linguistic Review. 